\title{
A SMEARED CRACK MODELLING APPROACH FOR AGGREGATE INTERLOCK AND MIXED MODE FRACTURE OF CONCRETE
}

\author{
J. UNGERMANN ${ }^{1}$, V. ADAM', J. HEGGER ${ }^{1}$ AND M. CLASSEN ${ }^{1,2}$ \\ ${ }^{1}$ RWTH Aachen University / Institute of Structural Concrete \\ Mies-van-der-Rohe-Str. 1 / 52074 Aachen / Germany \\ jungermann@imb.rwth-aachen.de \\ vadam@imb.rwth-aachen.de \\ jhegger@imb.rwth-aachen.de \\ mclassen@imb.rwth-aachen.de \\ ${ }^{2}$ KU Leuven / Department of Civil Engineering \\ Jan Pieter de Nayerlaan 5/ 2860 Sint-Katelijne-Waver / Belgium
}

Key words: Finite element analysis, 2D concrete material model, Aggregate Interlock, Concrete Cracking.

\begin{abstract}
The intention of this contribution is the numerical description of the rarely investigated phenomenon of mixed mode fracture in plain concrete. Since cracks in concrete are typically subjected to both normal and shear displacements, a new material model called fictitious rough crack model (FRCM) is proposed which combines mode I fictitious crack models with aggregate interlock models. For modelling the mixed mode behavior as the result of coexisting cohesive concrete behavior and aggregate interlock stresses along concrete cracks, mode I behavior is considered as the main influence on crack formation at the crack tip and mode II behavior (aggregate interlock) is assumed to occur when translations are induced along the crack surfaces (slip). The combination of these tension-softening and shear-transfer laws and the resulting shear and normal stresses of both mechanisms in the crack characterizes the main idea of the model. Well-known experimental benchmark problems are solved both for validation of the proposed model as well as for comparison with renowned concrete models of commercial FE software. The analysis shows that the FRCM can simulate the transition from mode I fracture to mixed mode fracture in the structural response while the comparison with commercial numerical approaches demonstrates the lack of appropriate consideration of aggregate interlock and mixed mode behavior in commercial FE software.
\end{abstract}

\section{INTRODUCTION}

\subsection{General}

The structural behavior of plain concrete is significantly influenced by its quasi-brittle nature and the localization and propagation of cracks which is usually assumed to occur by exceeding the uniaxial or multiaxial tensile strength of the material. After the beginning of concrete cracking, the kinematic behavior of the crack faces can be defined by different modes which 
are illustrated in Figure 1, namely mode I, often denoted as opening or tensile mode, and mode II, denoted as sliding or shear mode.

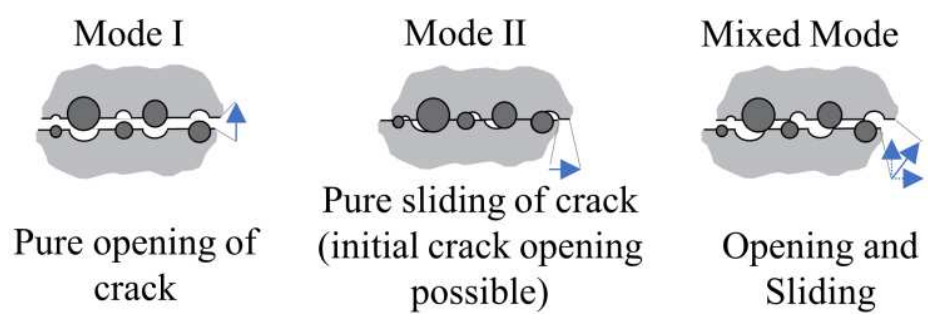

Figure 1: Illustration of the different crack modes according to [1].

Most fracture problems in concrete and reinforced concrete structures, as e.g., shear failures of RC beams, are of mixed mode nature, involving perpendicular (mode I) and parallel movements (mode II) of the crack surfaces concurrently. However, the modelling of shear and mixed mode fracture is not yet well developed for cementitious materials.

\subsection{Benchmark analysis for selected models}

The review of existing approaches to model tension and shear in cracked concrete (cf. [2]) clarified that especially aggregate interlock phenomena are rarely considered. In the following, frequently used concrete models provided by different commercial software packages are validated against Paulay's [3] ageregate nnterlock experiments in order to evaluate the models'
ability to capture mode II behavior. The following, widely used models are analyzed:
- Abaqus concrete damaged plasticity (CDP)
- ATENA constitutive modiel SBETA (CC\$betaMaterial)
- ATENA microplane material model (CCMicroplane4)

Selected properties of these material models are evaluated in Table 1 based on the theoretical

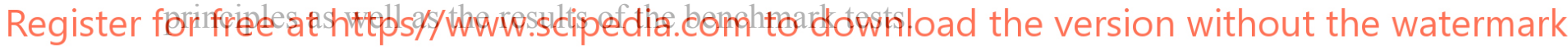
Table 1: Rating of material models against different criteria

\begin{tabular}{|c|c|c|c|}
\hline Model & $\begin{array}{l}\text { Concrete } \\
\text { damaged } \\
\text { plasticity }\end{array}$ & $\begin{array}{l}\text { ATENA constitutive } \\
\text { model SBETA } \\
\text { (CCSbetaMaterial) }\end{array}$ & $\begin{array}{c}\text { ATENA } \\
\text { Microplane } \\
\text { Material Model } \\
\text { (CCMicroplane4) }\end{array}$ \\
\hline
\end{tabular}

\begin{tabular}{ccccc}
\hline Nonlinear tension behavior & + & + & + \\
\hline Nonlinear compression behavior & + & + & + \\
\hline \multicolumn{2}{c}{ Biaxial concrete behavior } & + & + & + \\
\hline \multirow{2}{*}{$\begin{array}{c}\text { Aggregate } \\
\text { interlock }\end{array}$} & Normal & - & - & o \\
\cline { 2 - 5 } Crack model & - & o & F or R & $/$ \\
\hline
\end{tabular}

+ well considered; o simplified consideration; - unconsidered; $\mathrm{F}$ = fixed; $\mathrm{R}$ = rotated; / not assessable

While the smeared crack approach of CDP [4] considers mode I behavior by Hillerborg's fictitious crack model, CDP does not account for any shear transfer across smeared cracks under 
mode II deformations. The plane stress state model SBETA [5] uses a variable shear retention factor based on the crack width for a simplified consideration of shear stresses. In contrast, the frictional response of ATENA microplane model (M4) is based on strains and stresses on arbitrary planes [5-7] and can be controlled using fixed parameters for initial cohesion and their decrease depending on the volume expansion [7].

Figure 2 shows the comparison of the test results for a constant crack width of $0.25 \mathrm{~mm}$ with the numerical results of the selected models. The simulations were done with concrete strengths (cf. Figure 7e) and mesh size according to section 3.2. The used standard model parameters of the approaches are described in [2].
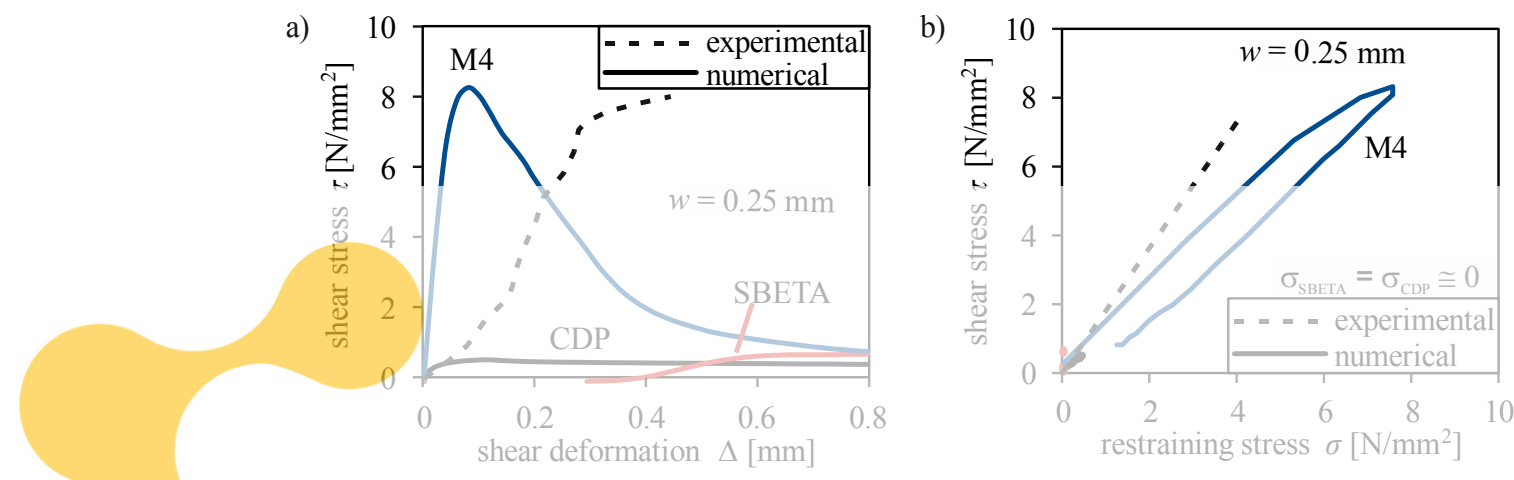

Figure 2: Results of benchmark test of Paulay [3] with constant crack width: a) shear stress- shear deformation
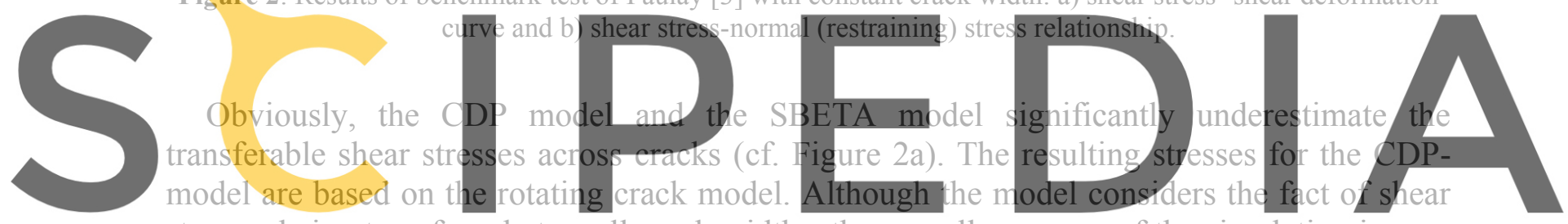

stresses being transferred at small crack widths, the overall accuracy of the simulation is very

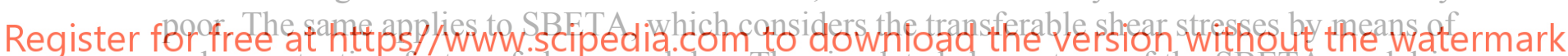
a shear retention factor of shear modulus. The simulated shear stress of the SBETA model in

Figure 2a starts with negative values and increases with growing shear deformation. The shear strength is limited by the maximum value of $f_{t}^{\prime}$ [5]. Both models (CDP and SBETA) seem inadequate to capture shear transfer across cracks. In addition, both models entirely disregard the occurrence of normal (restraint) stresses in Figure 2b.

The illustration of Paulay's experimental results with microplanes shows a significantly better accuracy, especially for the shear stress-restraining stress relationship in Figure $2 \mathrm{~b}$. The simulation of shear stress-deformation curve significantly deviates from test results since this model is based on material laws in normal direction and friction boundaries in shear direction on arbitrary planes with various orientations $[6,7]$. Although this definition apparently leads to a consideration of aggregate interlock phenomena with resulting normal stresses, it does not lead to a consistent description of the structural behavior due to the missing theoretical principles.

Conclusively, an accurate description of aggregate interlock effects is not possible with these well-known models described above. This is the motivation to aim at improving modelling approaches leading to the development of a new material model. 


\subsection{Development of fictitious rough crack model - FRCM}

To improve the numerical consideration of the aggregate interlock effects (cf. chapter 1.2), the paper presents a new smeared crack formulation to model shear transfer across cracks and mixed mode fracture of concrete (detailed presentation in [2]). The well-known biaxial material model by Darwin and Pecknold $[8,9]$ was therefore applied and combined with the fictitious crack approach of Hillerborg [10] for mode I behavior of concrete. The main idea is to combine these tension-softening laws (mode I) with shear-transfer laws (mode II, e.g. aggregate interlock model by Walraven $[11,12]$ or Bažant [13]) and to superpose the emerging shear and normal stresses of both mechanisms in the crack in order to simulate the mixed mode behavior of concrete. An illustrative five-step procedure of the "fictitious rough crack model - FRCM" for determining the stresses in the crack is shown in Figure 3.
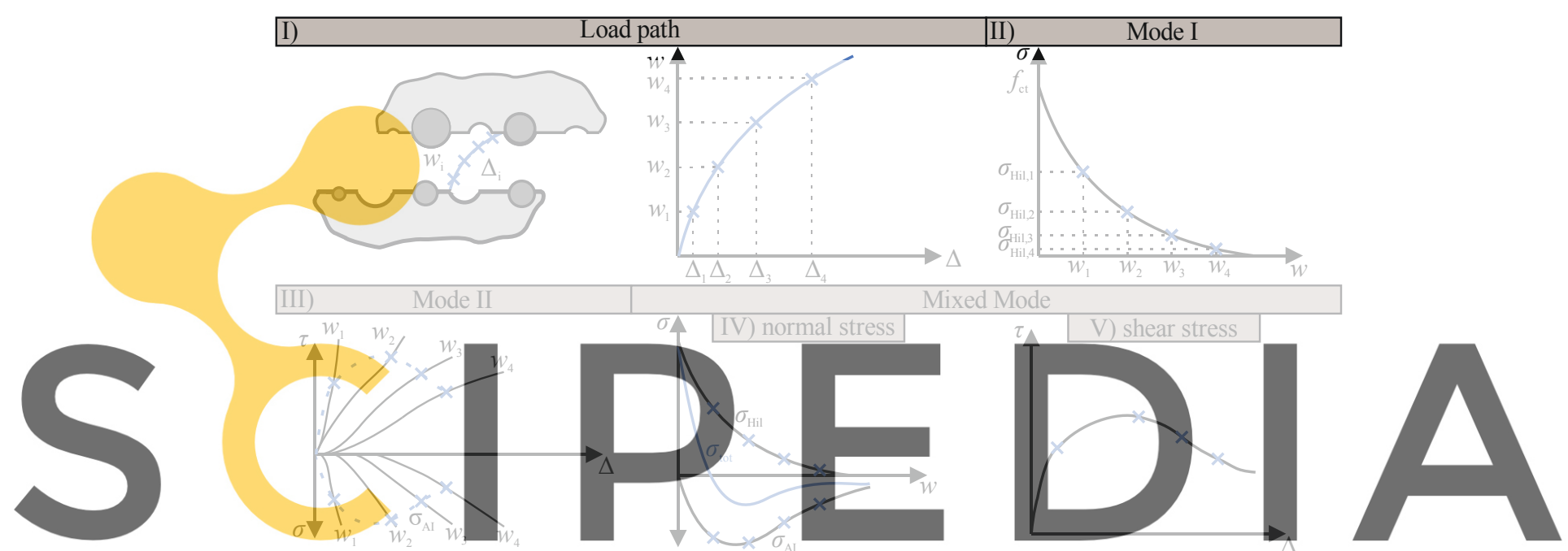

Figure 3: Key concept of FRCM, (I) definition of load path, (II) determination of tensile stresses, (III) pure shear

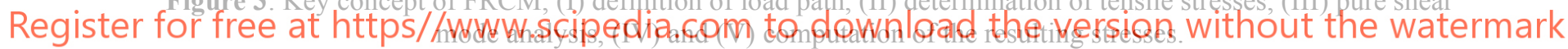

The five steps for determining the transmittable stresses are defined as follows:

Step I: The deformation path is given as a function of the two independent parameters of the shear deformation $\Delta$ and the crack opening $w$.

Step II: Initial determination of the crack stresses. The tensile stresses in the fracture process zone are determined using the fictitious crack model according to Hillerborg [10] (cf. Eq. (4)) which is based on the uniaxial tensile strength and the fracture energy in pure mode I condition at crack opening $w$.

Step III: Pure shear mode II is considered based on the relation of $w / \Delta$ with respect to the different aggregate interlock approaches (cf. Eq.(5) - (8)). This proper approach considers the interaction of shear and normal deformation for determining the resulting stresses in the crack.

Step IV: In this key step, mode I and II models are combined for mixed mode simulations by superposing the normal stresses of mode I $\sigma_{\mathrm{Hil}}$ with those of mode II $\sigma_{\mathrm{AI}}$. The blue total stress curve is then defined as the superposition of the two curves from the single modes I and II. 
Step V: The resulting shear stress curve is determined based on pure mode II (cf. Step III). Figure 3 thus describes the unique procedure and the key concept of the FRCM based on the following main assumptions:

1. The formation of cracks occurs under pure mode I conditions after exceeding the biaxial tensile strength.

2. A fixed crack model is applied.

3. After initial crack opening, Hillerborg's fictitious crack model is combined with appropriate aggregate interlock models based on crack surface deformations $\Delta$ and $w$.

The proposed model is implemented with the user-subroutine UMAT using Abaqus/Standard and validated by a comparison with current modelling approaches against experiments from literature. The key concept of FRCM is not limited to the approaches described below. Here, also more sophisticated material models are imaginable without limiting their general applicability.

\section{PRESENTATION OF THE CONCRETE MODEL}

\subsection{General equations of the two-dimensional material model}

The implemented two-dimensional concrete model is based on the biaxial material model of Darwin and Pecknold $[8,9]$ which uses equivalent uniaxial principal stress-strain relations for describing the material behavior. These curves define the principal tangential stiffnesses $E_{1}$ and

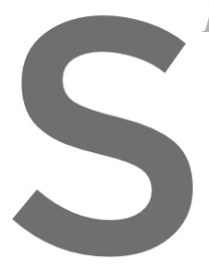
$E_{2}$ used for an orthotrop
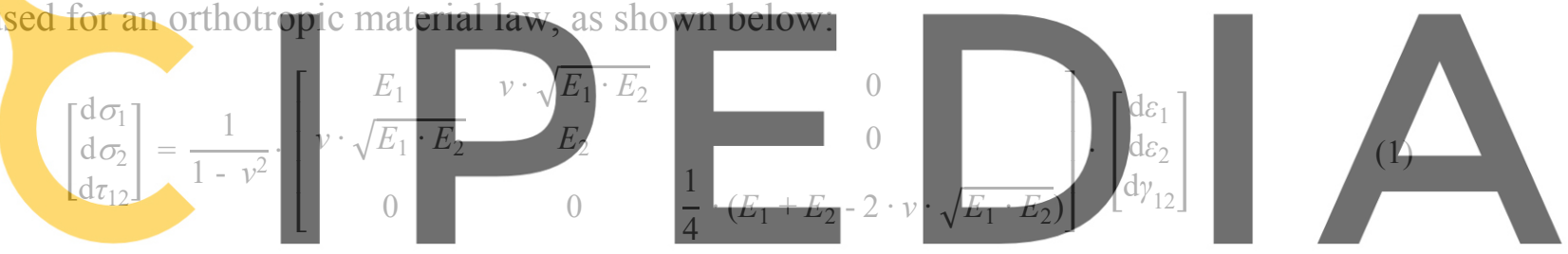

$E_{1}$ and $E_{2}$ are the stiffnesses determined from the equivalent stress-strain curve in principal

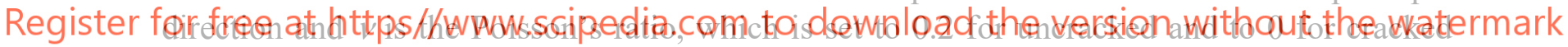
concrete $[14,15]$ leading the non-diagonal values to become zero. $\varepsilon_{1}$ is defined as the equivalent maximum principal strain and corresponds to the strain normal to the crack direction. $\varepsilon_{2}$ is defined as minimal principal strain while $\gamma_{12}$ is the shear strain, which is null if the concrete is non-cracked. The implemented model uses the implicit solving algorithm via the consistent Jacobian in UMAT for solving the tangential stiffness matrix. By using the transformation matrix, the principal stiffness matrix is converted to the axis directions as follows: $D^{\prime}=T^{\mathrm{T}} \cdot D \cdot T$.

\subsection{Material behavior in principal stress directions}

\section{Stress-strain relationships}

For a numerical description of the material behavior of concrete based on the equivalent stress-strain concept, analytical uniaxial stress-strain relations are needed. For compression, the expression by Darwin and Pecknold [8,9] is used which was derived and validated by experimental results of Kupfer, Hilsdorf, Rüsch [16] and Nelissen [17] (cf. Equation (2)). 


$$
\sigma=\frac{\varepsilon_{\mathrm{iu}} \cdot E_{0}}{1+\left(\frac{E_{0}}{E_{\mathrm{S}}}-2\right) \cdot \frac{\varepsilon_{\mathrm{iu}}}{\varepsilon_{\mathrm{ic}}}+\left(\frac{\varepsilon_{\mathrm{iu}}}{\varepsilon_{\mathrm{ic}}}\right)^{2}}
$$

$\varepsilon_{\text {ic }}$ is the equivalent strain belonging to the maximum biaxial compressive stress $\sigma_{\mathrm{ic}}, E_{0}$ the initial tangent stiffness, $E_{\mathrm{s}}$ the secant stiffness belonging to the maximum biaxial compressive stress $\sigma_{\mathrm{ic}}$ and $\varepsilon_{\mathrm{iu}}$ is the equivalent strain, which is calculated as input value according to equation (3).

$$
\varepsilon_{\mathrm{iu}}=\int \frac{\mathrm{d} \sigma_{\mathrm{i}}}{E_{\mathrm{i}}}=\sum_{\substack{\text { all } \\ \text { load increments }}} \frac{\Delta \sigma_{\mathrm{i}}}{E_{\mathrm{i}}}
$$

$E_{\mathrm{i}}$ is the tangent stiffness. The equivalent strain concept according to Darwin and Pecknold $[8,9]$ serves to isolate the Poisson effect from the cumulative strains. This allows for determining the true plane biaxial stress-strain state for concrete by using the given equivalent stress-strain relations (e.g., Equation (2)). A linear-elastic predictor stress for $\Delta \sigma_{1}$ is used at the beginning of the subroutine determining the required nonlinear stress $\varepsilon_{\text {iu }}$.

While the material behavior of non-cracked concrete under tensile loads is assumed to be linear-elastic, the definition of the cracked tensile behavior is based on the fictitious crack model of Hillerborg [10] (cf. Figure 4d). A stress-displacement (crack width) relation is used to describe the post-cracking behavior in the fracture zone. To avoid singularity and other numerical problems exponential function
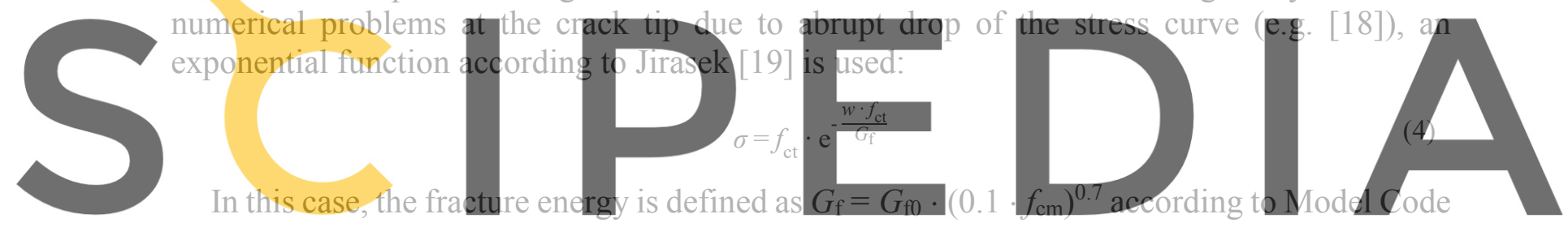

In this case, the fracture energy is defined as $G_{\mathrm{f}}=G_{\mathrm{fo}} \cdot(0.1$

90 [20] (other approaches e.g. [20-22]), $w$ is the crack width, $f_{\text {ct }}$ is the uniaxial tensile strength

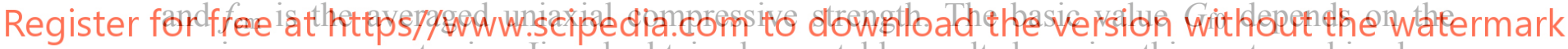
maximum aggregate size. Jirasek obtained acceptable results by using this post-cracking law. In cases where fracture energy properties were documented, these values were considered in the numerical simulations.

\section{Biaxial mechanical properties}

The concrete behavior under biaxial stress state is characterized by a change in stiffness and strength. In case of biaxial compression, increased stiffness as well as increased strength is observed, which can reach values up to 1.16-times the uniaxial strength. The influence of biaxial stress states is taken into account with Kupfer's modified analytical strength envelope $[8,9]$ shown in Figure 4a [23]. The biaxial strength values are thus calculated depending on the main stress state, which is described by $\alpha=\sigma_{1} / \sigma_{2}$. The ductility variation of concrete exposed to biaxial stress conditions is considered according to [8,9] (see also [2]).

\subsection{Modelling of cracked concrete behavior}

The cracked concrete behavior is realized by adjusting equation (1) to an orthotropic constitutive law based on smeared fixed crack model approaches $(v=0)$ [2]. This tangential 
matrix is used for incremental computation of the predictor step while the Jacobian matrix needed for the implicit solving algorithm is numerically determined. The nonlinear stresses are computed according to the given stress-strain relations in chapter 2.2.

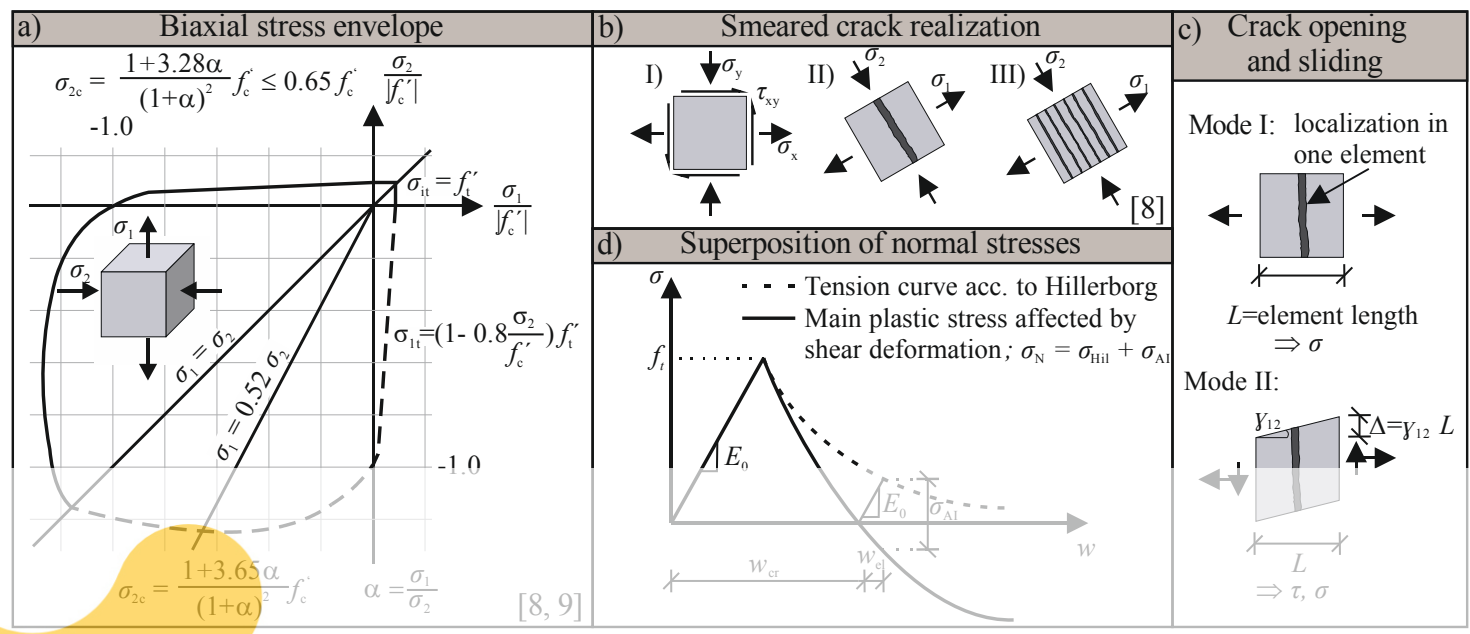

Figure 4: Theoretical Background of the fictitious rough crack model (FRCM), a) biaxial strength envelope acc. to $[8,9]$, b) smeared crack idealization acc. to [8], c) definition of crack displacements and d) superposition of normal stresses in the crack.
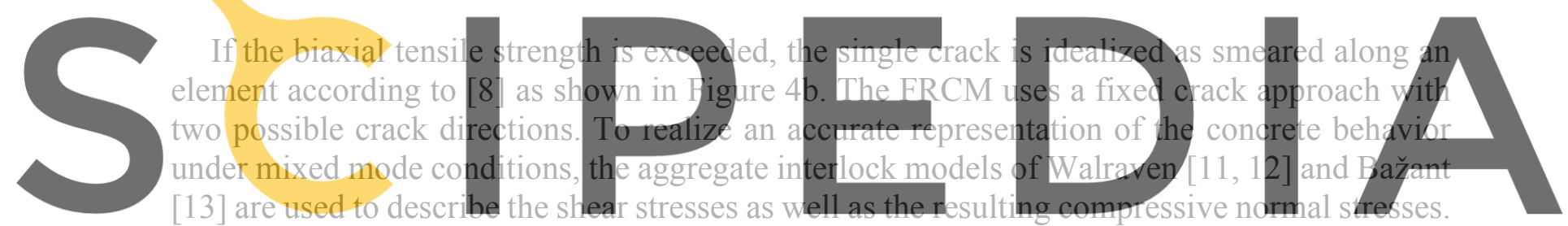

Both models consider the interaction between normal and shear deformations. The smeared

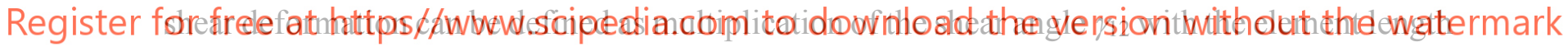

$L$ referring to a discrete description of a crack (cf. Figure 4c). Due to negative normal stresses caused by aggregate interlock, assessing the crack width is more complicated than in case of pure mode I behavior [10]. To use the post cracking behavior, the compressive normal stress due to aggregate interlock $\sigma_{\mathrm{AI}}$ must be subtracted from the total normal stress (cf. Figure $4 \mathrm{~d}$ ).

The central approach of FRCM (cf. Figure 3) consists in the superposition of the resulting tensile stresses $\sigma_{\mathrm{N}}$ of mode I according to Hillerborg $\sigma_{\mathrm{Hil}}$ and mode II according to aggregate interlock models $\sigma_{\mathrm{AI}}$ (cf. Figure 4d). Due to the crack formation control by pure mode I through the stress-crack opening displacement curve (e.g., $[10,15,24,25])$, the definition of shear deformation of the crack faces with the element length per element does not cause mesh dependencies. Different approaches can be used for defining the transmittable stresses $\sigma_{\text {AI }}$ due to aggregate interlock. Walraven $[11,12]$, for example, used a probability distribution of the aggregates in the concrete as well as a Fuller curve. His approach therefore considers the maximum aggregate size, the matrix strength and consequently the crucial influence of the concrete composition on the mechanism of aggregate interlock. Walraven's simplified equations based on his experimental results are considered in this paper (cf. Equations (5) and (6)). 


$$
\begin{gathered}
\tau=-\frac{f_{\mathrm{cc}}^{\prime}}{30}+\left[1.8 \cdot w^{-0.8}+\left(0.234 \cdot w^{-0.707}-0.20\right) \cdot f_{\mathrm{cc}}^{\prime}\right] \cdot \Delta>0 \\
\sigma=-\frac{f_{\mathrm{cc}}^{\prime}}{20}+\left[1.35 \cdot w^{-0.63}+\left(0.191 \cdot w^{-0.552}-0.15\right) \cdot f_{\mathrm{cc}}^{\prime}\right] \cdot \Delta>0
\end{gathered}
$$

Here, $f^{\prime}$ cc is the cube compressive strength, $w$ is the crack width and $\Delta$ is the shear deformation. These equations are valid for maximum aggregate sizes between 16 and $32 \mathrm{~mm}$.

Bažant's [24] model was derived from Paulay's [3] experimental test data with maximum aggregate size of $19 \mathrm{~mm}$ according to Equations (7) and (8).

$$
\begin{aligned}
& \sigma_{\mathrm{nt}}^{\mathrm{c}}=\tau=\tau_{\mathrm{u}} \cdot r \cdot \frac{a_{3}+a_{4} \cdot|r|^{3}}{1+a_{4} \cdot r^{4}} \\
& \sigma_{\mathrm{nn}}^{\mathrm{c}}=\sigma=-\frac{a_{1}}{\delta_{\mathrm{n}}} \cdot\left(a_{2} \cdot\left|\sigma_{\mathrm{nt}}^{\mathrm{c}}\right|\right)^{\mathrm{p}}
\end{aligned}
$$

Equations (7) and (8) (Notations adopted from Bažant) mainly depend on the ratio $r$ between shear and normal deformation as well as the maximum shear stress $\tau_{\mathrm{u}}=0.245 \cdot f_{\mathrm{c}}{ }^{\prime}\left(a_{1}\right.$ to $a_{4}$ are constants). Verified theoretical models describing the aggregate interlock mechanisms in case of concrete or mortar compositions with smaller maximum aggregate sizes are currently lacking.
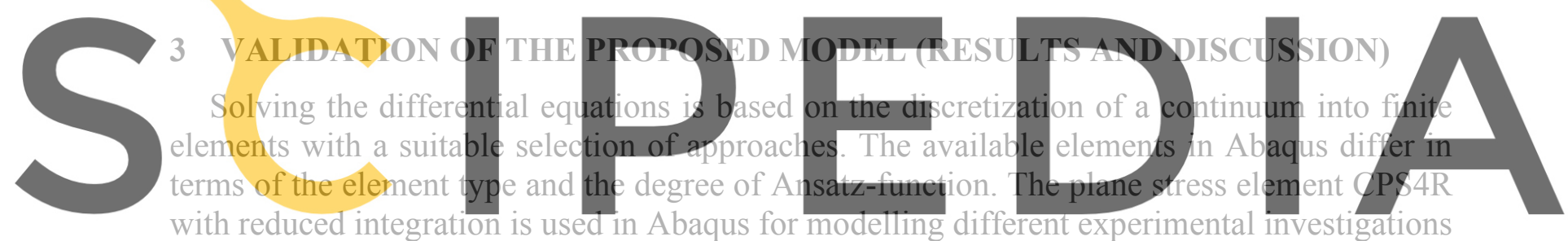

with reduced integration is used in Abaqus for modelling different experimental investigations for validation.

Register for free at https//www.scipedia.com to download the version without the watermark

\subsection{Comparison with analytical solutions for one single element}

The first step to validate the implemented material model was to validate the implemented constitutive equations by applying different load combinations on one single $5 \times 5(\mathrm{~mm})$ finite element. Material parameters of $E=30000 \mathrm{~N} / \mathrm{mm}^{2}, f_{\mathrm{c}, \mathrm{cyl}}=25 \mathrm{~N} / \mathrm{mm}^{2}, f_{\mathrm{ct}}=3 \mathrm{~N} / \mathrm{mm}^{2}$, $G_{\mathrm{f}}=0.06 \mathrm{~N} / \mathrm{mm}$ and a maximum uniaxial concrete compressive strain of $\varepsilon_{\mathrm{cu}}=2.2 \%$ are used. Displacement loads are applied for verification of descending branch so that the stress ratio is transformed into a strain ratio $\varepsilon_{1} / \varepsilon_{2}=(\alpha-v) /(1-\alpha \cdot v)$ by use of the stiffness matrix in equation (1) and assuming $E_{1}=E_{2}$.

To validate the implemented shear and mixed mode behavior based on the combination of mode I and II, two different load cases were examined. Before applying pure shear mode, the element was first cracked in mode I until reaching a crack width of $0.1 \mathrm{~mm}$. Subsequently, pure shear loading was applied while maintaining a constant crack width. The numerical results agree with the analytical solutions of the aggregate interlock model of Walraven (cf. Figure 5a) and Bažant (cf. Figure 5b). The influence of the linear regression formulae of Walraven [11, 12] without an upper limit of transferable shear stress can be seen in Figure 5a. The application of Bažant's rough crack model [24] in FRCM in Figure 5b considers an upper limit of 
transferable shear stress and leads to a more realistic behavior. Nonetheless, in real load conditions, this upper limit value is probably not decisive as shown in Figure 5c, d. Here, a constant relation between normal and shear deformation was applied (after first loading until the tensile strength was reached) to assume the expected mixed mode conditions. Mixed mode loading paths with shear and normal displacements in a ratio of $\Delta / w=2 / 1$ cause a parabolic curve with descending branch in dependence of the interaction between $\Delta$ and $w$. With increasing crack width $w$, the transmittable stresses decrease as expected. The numerical solution is in perfect compliance with the analytical solution (cf. Figure 5).
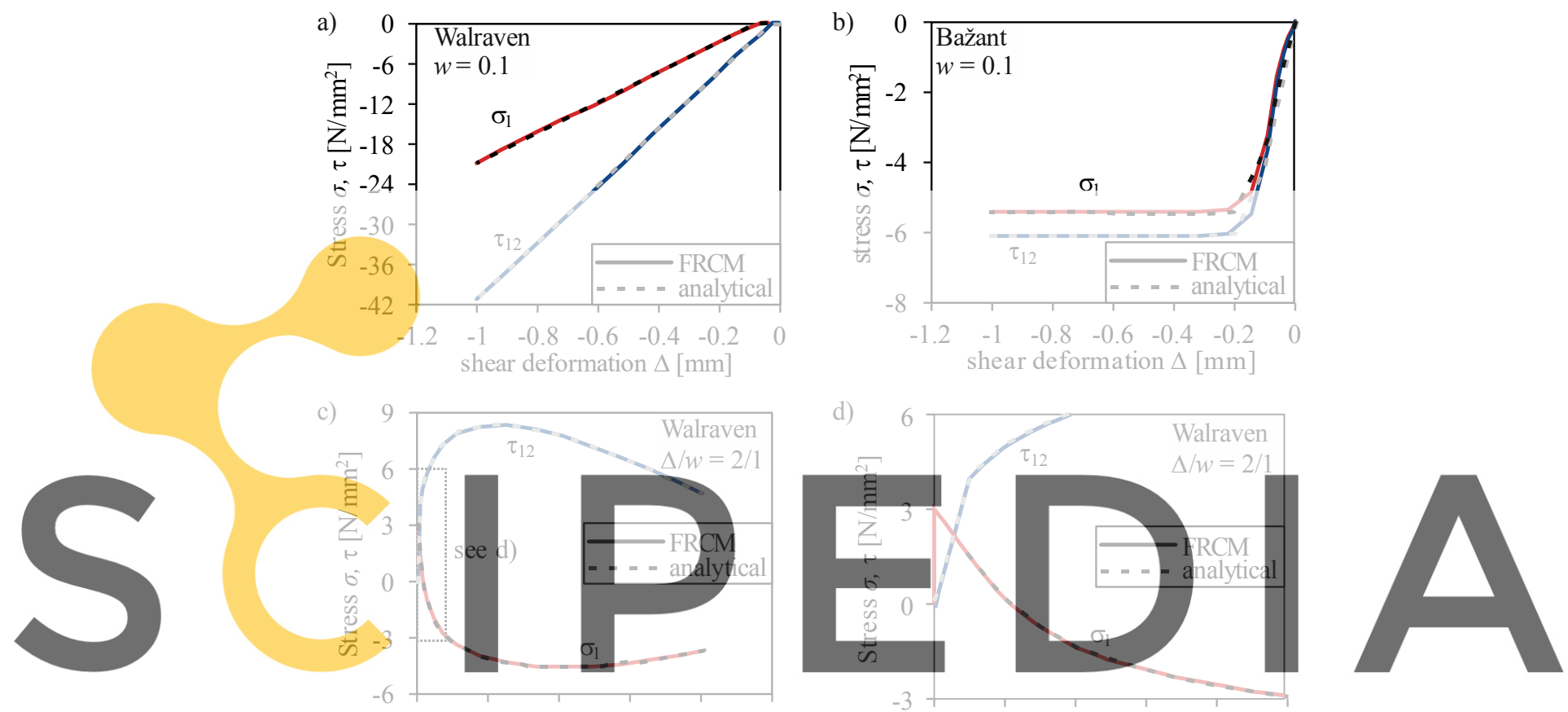

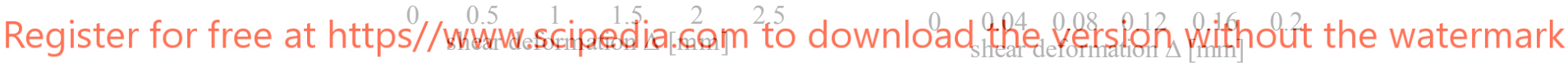

Figure 5: Illustration of numerical verification results compared to theoretically analytic solution for a) \& b) shear with constant crack width and c) \& d) constant tension-shear condition, FRCM with Walraven's or Bažant's aggregate interlock model.

Validation of the biaxial material behavior in principal stress directions can be found in [2].

\subsection{Validation with benchmark tests}

Additionally, different experimental investigations were recalculated to validate the implemented FRCM. The used material parameters and test setups are shown in Figure 6a and Figure 7e. All validations were conducted with a discretization of the entire experimental specimens using a mesh size between 4 and $10 \mathrm{~mm}$ based on the specimen sizes. The load was applied with a maximum increment size of 0.1 , while the lower limit was set to $10^{-30}$.

\section{Behavior under normal stresses: biaxial stress state experiments of Kupfer}

The experiments by Kupfer [16] are used for verification of biaxial material behavior of the proposed model. The simulation results are compared against Kupfer's biaxial strength 
envelope in Figure $6 \mathrm{~b}$. The maximum stresses obtained from the experiments are slightly overestimated for the tension-compression case. The minimum compressive strength of $0.65 \cdot f_{\mathrm{c}, \mathrm{cyl}}$ according to Darwin and Pecknold's [8] modified strength envelope (cf. Figure 4a) acts in that case like a lower limit of $65 \%$ of uniaxial compressive strength for increasing tensile stress while the tensile strength increases for decreasing compressive stresses. This leads to an overestimation with increasing $\alpha$-ratio (cf. Section 2.2).

a)

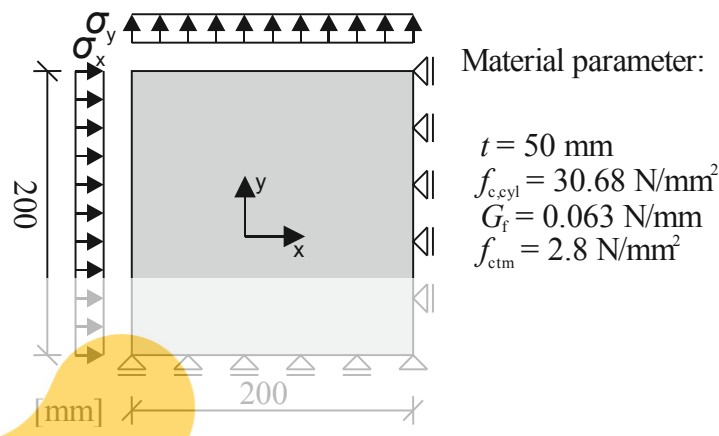

b)

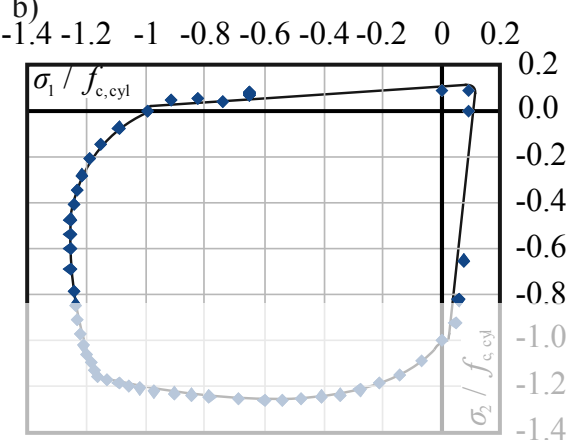

Figure 6: a) Hlustration of the numerical boundary conditions and b) numerical results compared to the strength envelope according to [16].

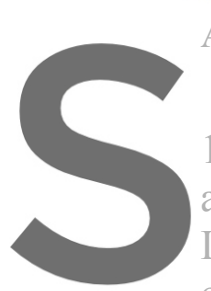

Aggregate interlock experiments of Paulay

To confirm that the

12] and Bažant [13] is

aggregate diameters,

Loeber [3] with an a

constant in the tests while loading was applied

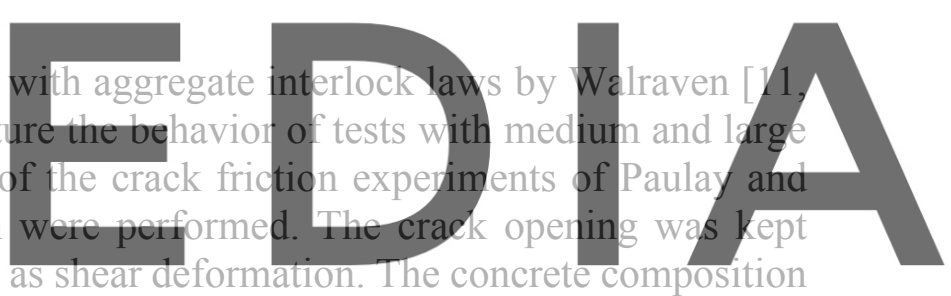

corresponds to the used aggregate interlock laws of Walraven [11, 12].and Bažant [13]. Figure

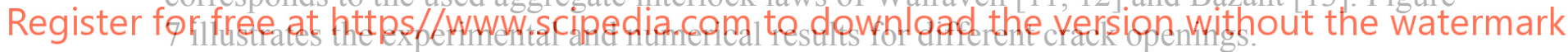

Here, Figure 7a,b show the relation between transferable shear stress and shear deformation

while Figure $7 \mathrm{c}$,d show the resuiting restraining compressive stresses in relation to the shear stresses. The experimental results represent the averaged values, where the shear deformations were experimentally determined above and below the crack. Using the aggregate interlock laws by Bažant (cf. Figure 7a) and Walraven (cf. Figure 7b), the FRCM predicts the transferred shear stresses as well as the resulting normal compressive stresses for all crack openings with reasonable agreement. For the effect of compressive normal stresses, illustrated in Figure 7c,d, the application of the FRCM in combination with Bažant's aggregate interlock model gives the best prediction of experimental results, while Walraven's model requires higher shear deformations to activate compressive stresses. 
a)

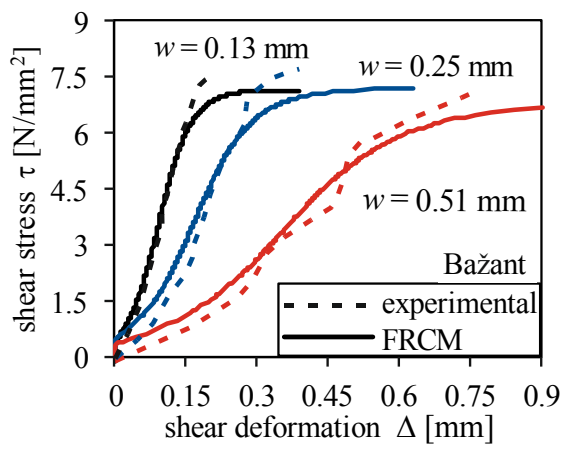

c)

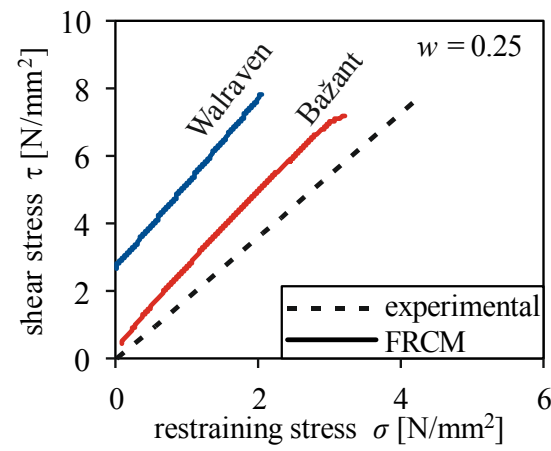

b)

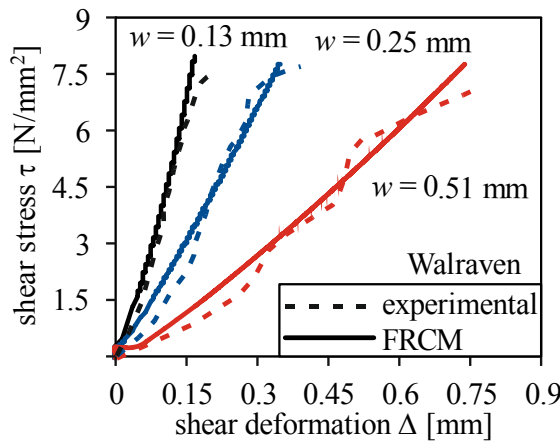

d)

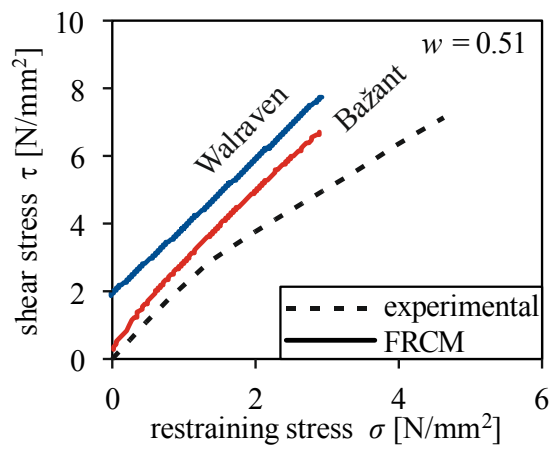

e) Paulay:

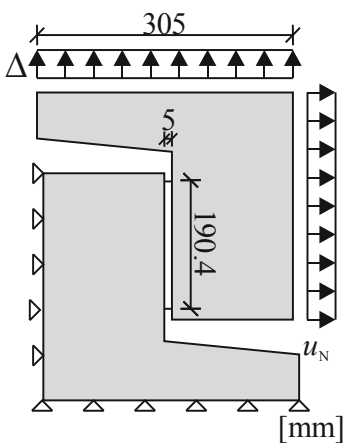

Material parameter:

$t=152 \mathrm{~mm}$

$f_{\mathrm{c}, \mathrm{yyl}}=28.5 \mathrm{~N} / \mathrm{mm}^{2}$

$G_{\mathrm{f}}=0.066 \mathrm{~N} / \mathrm{mm}$

$f_{\text {ctm }}=2.8 \mathrm{~N} / \mathrm{mm}^{2}$

Figure 7: Comparison of numerical results with FRCM (aggregate interlock models by Walraven and Bažant) and experimental results: shear stress-deformation for a) Bažant, b) Walraven and relation of shear stress and restraining stress for c) $w=0.25$ and d) $w=0.51$.

\section{CONCLUSIONS}

The application of Finite-Element-Method has become more and more important while less attention has been paid to the numerical representation of shear and mixed mode behavior of concrete. In this contribution, frequently used concrete models implemented in commercial FE software are assessed regarding the aggregate interlock behavior of concrete by applying these models to the benchmark test of Paulay with a constant crack width. The following conclusions can be drawn:

- Commercial models (Abaqus CDP, ATENA SBETA, ATENA Microplane4) show significant lack of prediction of aggregate interlock effects due to oversimplification of the underlying mechanisms.

- The use of shear retention factors leads to unsatisfactory results and does not solve the problem of complex interaction of crack deformations.

- The crack friction or mixed mode behavior is decisively influenced by the behavior of the crack surfaces. Opposing simplified approaches, the interaction of shear and normal deformation is of particular significance for the transmittable stresses in the fracture process zone.

To overcome the drawbacks of aforementioned numerical approaches, the paper presents a two-dimensional numerical material model named fictitious rough crack model (FRCM) for prediction of mode II and mixed mode behavior of concrete. The FRCM, implemented in ABAQUS by user subroutine UMAT, considers a new smeared crack formulation based on Darwin and Pecknolds' biaxial material model. It is extended by the fictitious crack model by 
Hillerborg and constitutive models for aggregate interlock by either Walraven's two phase model or Bažant's rough crack model. The intention of the presented studies was to deepen the understanding of aggregate interlock effects in mixed mode cracking and to clarify the unsatisfying consideration in common models of commercial software. It has been shown that the FRCM approach is able to adequately capture the fundamental principles of mode II and mixed mode behavior and shows reasonable agreement with experimental results. Additionally, the FRCM allows different possibilities for determining the aggregate interlock behavior of concrete and hence enables to react to different concrete compositions when theoretical models are available.

The FRCM is a first and humble approach to improve the understanding of aggregate interlock effects, which show potential of a refined numerical analysis of the mixed mode behavior of concrete. It is intended as a motivation for further studies regarding the theoretical principles of aggregate interlock and mixed mode behavior as well as their refined consideration in analytical and numerical models.

\section{ACKNOWLEDGEMENTS}

This research work has been funded by the German research foundation (DFG) and is part of the research project "Punching shear behavior of eccentrically loaded footings" (project number 396630727, HE2637/31-1). The author would like to gratefully acknowledge the support.

\section{REFERENCES}

[1] Classen, M., Adam, V. and Hillebrand, M. Test Setup to Investigate Aggregate Interlock and Mixed Mode Fracture of Monolithic and 3D-Printed Concrete. In Proceedings of the fib Symposium (Krakow, 2019), 521-528.

[2] Ungermann, J., Adam, V. and Classen, M. Fictitious Rough Crack Model (FRCM): A Smeared Crack Modelling Approach to Account for Aggregate Interlock and Mixed Mode Fracture of Plain Concrete. Materials (Basel), 13, 12 (Jun 18 2020).

[3] Paulay, T. and Loeber, P. J. Shear transfer by aggregate interlock. American Concrete Institute, Shear in reinforced concrete, Publication SP-42 (1974), 1-15.

[4] Abaqus 6.14 Online Documentation, Abaqus Analysis User's Guide. Dassault Systems, City, Version 23.04.2014.

[5] ATENA Program Documentation Part I Theory. Cervenka Consulting, City, Version 26.01.2018.

[6] Bažant, Z. P., Caner, F. C., Carol, I., Adley, M. D. and Akers, S. A. Microplane model M4 for concrete. I: Formulation with work-conjugate deviatoric stress. Journal of Engineering Mechanics-Asce, 126, 9 (Sep 2000), 944-953.

[7] Ferhun, C. C. and Bazant, Z. P. Microplane Model M4 for concrete. II: Algorithm and Calibration. Journal of Engineering Mechanics, 126 (2000), 954-961.

[8] Darwin, D. and Pecknold, D. A. Inelastic Model for cyclic biaxial loading of reinforced concrete. University of Illionois, 1974.

[9] Darwin, D. and Pecknold, D. A. Nonlinear Biaxial Stress-Strain Law for Concrete. J Eng Mech Div-Asce, 103, 2 (1977), 229-241. 
[10] Hillerborg, A., Modéer, M. and Petersson, P.-E. Analysis of crack formation and crack growth in concrete by means of fracture mechanics and finite elements. Cement and Concrete Research, 6 (1976), 773-782.

[11] Walraven, J. Aggregate Interlock- A theoretical and experimental Analysis. PhD-Thesis, TU Delft, Delft, 1980.

[12] Walraven, J. C. Fundamental Analysis of Aggregate Interlock. J Struct Div-Asce, 107, 11 (1981), 2245-2270.

[13] Bažant, Z. P. and Gambarova, P. Rough cracks in reinforced concrete. Journal of the Structural Division, Asce, 106, No. ST4 (1980), 819-842.

[14] Hendriks, M. A. N., de Boer, A. and Belletti, B. Guidelines for Nonlinear Finite Element Analysis of Concrete Structures. Report RTD:1016-1:2017, Rijkswaterstaat Centre for Infrastructure, 2017.

[15] Huang, Z., Lü, Z., Song, S., Tu, Y., Blanksvärd, T., Sas, G. and Elfgren, L. Finite element analysis of shear deformation in reinforced concrete shear-critical beams. Structure and Infrastructure Engineering, 14, 6 (2017), 791-806.

[16] Kupfer, H., Hilsdorf, H. K. and Rüsch, H. Behavior of concrete under biaxial stresses. Journal American Concrete Institute, Proceedings, 66, 8 (1969), 656-666.

[17] Nelissen, L. J. M. Biaxial testing of normal concrete. HERON, 18, 1 (1972), 1-90.

[18] Weihe, S., Kroplin, B. and De Borst, R. Classification of smeared crack models based on material and structural properties. International Journal of Solids and Structures, 35, 12 (Apr 1998), 1289-1308.

[19] Jirásek, M. Damage and smeared crack models. SpringerWienNewYork, International Centre for mechanical Sciences, City, 2011.

[20] CEB-FIP Model Code 1990. Comite Euro-International du beton, City, 1991.

[21] Bažant, Z. P. and Pfeiffer, P. A. Determination of fracture energy from size effect and brittleness number. ACI Materials Journal, 84, 6 (1987), 463-480.

[22] Concrete, I. F. f. S. fib Model Code for Concrete Structures. Ernst \& Sohn, City, 2013.

[23] Kupfer, H. and Gerstle, H. Behavior of concrete under biaxial stresses. J Eng Mech DivAsce, 99, 4 (1973), 853-866.

[24] Bažant, Z. P. and Oh, B. H. Crack band theory for fracture of concrete. Mater Struct, 16, 3 (1983), 155-177.

[25] Rots, J. G. and Blaauwendraad, J. Crack Models for concrete: discrete or smeared? fixed, multi-directional or rotating? HERON, 34, 1 (1989), 1-59. 